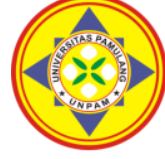

\title{
ANALISIS PELATIHAN UNTUK MENINGKATKAN PRODUKTIVITAS KERJA KARYAWAN DIVISI HUMAN CAPITAL PADA PT SUMBER ALFARIA TRIJAYA TBK (HEAD OFFICE) ALAM SUTERA KOTA TANGERANG
}

\author{
${ }^{1 *}$ Pusporini Palupi J, ${ }^{2}$ Elsa Miranda N \\ Universitas Pamulang, Tangerang Selatan, Banten Indonessia \\ *dosen01399@unpam.ac.id
}

\begin{abstract}
Abstrak
Penelitian ini menggunakan pendekatan dengan metode kualitatif. Mengumpulkan dan mengolah data dilakukan dengan cara observasi, interview, dokumentasi dan Triangulasi. Hasil penelitian menyatakan bahwa kegiatan pelatihan belum optimal. Diharapkan instruktur pelatihan dapat menumbuhkan motivasi karyawan dalam mengikuti kegiatan pelatihan. Diperlukan tambahan atau perubahan metode instruktur dalam menyampaikan materi pelatihan. Serta diperlukan kebijakan perusahaan yang mengatur peserta wajib mengikuti jadwal pelatihan yang telah ditentukan perusahaan. Mengenai Produktitvitas kerja divisi Human Capital pada PT Sumber Alfaria Trijaya Tbk belum optimal, belum sesuai dengan yang diharapkan perusahaan. Menurut hasil penelusuran yang peneliti lakukan, masih banyak karyawan yang kurang disiplin waktu, kurang loyal memprioritaskan yang menjadi aspek penilaian, dan minim komunikasi serta kurang motivasi untuk mengembangkan ilmu serta kemampuannya.
\end{abstract}

Kata Kunci: SDM, Pelatihan, Produktivitas Kerja

\section{Abstract}

This research uses an approach with qualitative methods. Collecting and processing data is done by observation, interview, documentation and triangulation. The results stated that the training activities have not been optimal. It is expected that training instructors can foster employee motivation in participating in training activities. Additional or changing of the instructor's methods in delivering training materials is required. As well as the company policy that regulates participants must follow the training schedule that has been determined by the company. Regarding the product of the work of the Human Capital division at PT Sumber Alfaria Trijaya Tbk has not been optimal, not yet in accordance with the company's expected. According to the results of the search conducted, there are still many employees who lack time discipline, less loyal priority that becomes the assessment aspect, and lack communication and lack motivation to develop their knowledge and abilities.

Keywords: Human Resources, Training, Work Productivity

\section{PENDAHULUAN}

Sumber daya manusia sering disebut sebagai human resource, tenaga atau kekuatan manusia (energi atau power). Sumber daya juga disebut sumber tenaga, kemampuan, kekuatan, keahlian yang dimiliki oleh manusia. Seiring dengan perkembangan teknologi dan perubahanperubahan dunia yang semakin hari semakin kompleks, menuntut seseorang untuk selalu merefresh kembali kemampuan yang dimilikinya sesuai dengan kapasitas perubahan tersebut.

Sebaliknya, suatu organisasi juga akan semakin maju dan berkembang apabila sumber daya yang dimiliki oleh karyawannya baik dan berkualitas. Karyawan dalam suatu organisasi memiliki kemampuan yang beragam, dilihat dari sektor-sektor ataupun divisi yang ditempatinya. Perkembangan dibidang teknologi dan ilmu pengetahuan membuat organisasi harus semakin peka dalam peningkatan kualitas sumber daya yang dimilikinya. Tak jarang pula sumber daya manusia atau karyawan yang menduduki jabatan tertentu dalam organisasi mempunyai kemampuan yang 
sesuai dengan persyaratan yang diperlukan.

Pelatihan dan pengembangan dilakukan sebagai upaya meningkatkan keterampilan dan pengetahuan yang dimiliki karyawan. Terutama menghadapi kondisi-kondisi baru. Hal ini berkaitan dengan karir dan diharapkan sebagai upaya dalam mengatasi adanya kadaluwarsa sumber daya manusia pada organisasi tersebut. Sebagai wujud pemenuhan kebutuhan pada karyawan yaitu kebutuhan untuk mengembangkan diri (aktualisasi diri) yang nantinya terkait dengan pengembangan karir karyawan.

Andrew E. Sikula dalam Mangkunegara (2017:43) menyatakan "Pelatihan adalah suatu proses pendidikan jangka pendek yang menggunakan prosedur sistematik dan terorganisir dimana pegawai non manajerial mempelajari pengetahuan dan ketrampilan teknis dalam tujuan terbatas".

Badriyah (2015:182) juga menyebutkan "Sumber daya manusia memegang peranan utama untuk dalam

Pada evaluasi produktivitas kerja poin komunikasi yang baik dari 2017 sampai 2019 pencapaian star masih sama yaitu 3 star, dalam artian dari 2017 sampai 2019 tidak ada peningkatan pada point komunikasi yang baik oleh Divisi Human Capital. penelitian yang telah diuraikan sebelumnya, maka peneliti tertarik untuk

\section{Pelatihan}

Secara umum pelatihan SDM bertujuan untuk menyediakan pekerja yang siap pakai baik dari sisi kompetensi, manajerial, maupun perilaku, sehingga memberikan kontribusi positif bagi perusahaan yang secara terus menerus sesuai dengan perkembangan persaingan dan jabatan. Pelatihan SDM juga bertujuan untuk dapat menyiapkan kaderisasi bagi jabatan-jabatan yang akan dikembangkan perusahaan di masa yang akan datang, sehingga pada saatnya tidak memerlukan waktu untuk pengisian jabatan tersebut. proses peningkatan produktivitas kerja. Sedangkan produktivitas kerja adalah perbandingan antara hasil yang dicapai dengan peran serta tenaga kerja persatuan waktu".

PT Sumber Alfaria Trijaya Tbk (Alfamart/Perseroan), mengawali usahanya di bidang perdagangan dan distribusi, Alfamart adalah gerai komunitas, karenanya selalu berpartisipasi dalam meningkatkan kesejahteraan masyarakat melalui program Tanggung Jawab Sosial Perusahaan (CSR) yang terbagi menjadi Alfamart Care yang membantu masyarakat melalui kegiatankegiatan sosial. Alfamart Smart mendukung bidang pendidikan, Alfamart Sport mensponsori kegiatan olahraga, Alfamart Clean and Green mewujudkan lingkungan yang sehat, Alfamart SMEs membantu pengusaha kecil dan menengah yang ada di sekitar gerai-gerai Alfamart serta Alfamart Vaganza yang secara aktif ikut terlibat dalam pengembangan seni dan budaya.

melakukan penelitian lebih lanjut yang hasilnya akan peneliti tuangkan dalam berjudul "Analisis Pelatihan untuk Meningkatkan Produktivitas Kerja Karyawan Divisi Human Capital pada PT Sumber Alfaria Trijaya Tbk (Head Office) Alam Sutera Kota Tangerang".

\section{TINJAUAN PUSTAKA}

\section{Produktivitas}

Produktivitas

adalah perbandingan antara hasil kerja yang berupa barang- barang atau jasa dengan sumber atau tenaga yang dipakai dalam suatu proses produksi tersebut. Sedangkan menurut penelitian formulasi National Productivity Board Singapure, dikatakan bahwa produktivitas adalah sikap mental yang mempunyai semangat untuk melakukan peningkatan perbaikan. 


\section{METODE PENELITIAN}

Penelitian ini menggunakan metode kualitatif. "Metode penelitian pada dasarnya merupakan cara ilmiah untuk mendapatkan data dengan tujuan dan kegunaan tertentu" Sugiyono (2018:347). Berdasarkan hal tersebut, terdapat empat kata kunci yang perlu diperhatikan yaitu cara ilmiah, data, tujuan dan kegunaan. "Penelitian kualitatif adalah jenis penelitian yang mengeksplorasi dan memahami makna di sejumlah individu atau sekelompok orang yang berasal dari masalah sosial" Creswell dalam Sugiyono (2018:347). Penelitian kualitatif secara umum dapat digunakan untuk penelitian tentang kehidupan masyarakat, sejarah, tingkah laku, konsep atau fenomena, masalah sosial, dan lain-lain.

"Populasi sebagai suatu kelompok besar dari kesatuan sampel yang hendak diteliti" Neuman dalam Herdiansyah (2018:103). populasi hanya beberapa orang yang paling mendekati karakteristik, karena keterbatasan sumber daya manusia, keterbatasan waktu penelitian, keterbatasan biaya, dan kurangnya efisiensi peneliti apabila meneliti semua makna yang ada. Populasi yang terdapat di Divisi Human Capital PT Sumber Alfaria Trijaya Tbk (HO) Alam Sutera Kota Tangerang berjumlah 181 orang. Situasi sosial tersebut dapat dinyatakan sebagai objek penelitian yang ingin diketahui "apa yang terjadi" di dalamnya.

Sampel dalam penelitian kualitatif bukan dinamakan responden, tetapi sebagai narasumber, partisipan, informan, teman dan guru dalam penelitian. Sampel dalam penelitian kualitatif bukan disebut sampel statistik Karakteristik sampel yang akan dipilih berdasarkan sebagai berikut:

1. Memiliki riwayat mengikuti pelatihan sebanyak 3 kali.

2. Memiliki masa kerja 3 - 9 Tahun.

3. Memiliki jabatan Staff, Cordinator, Manager.

4. Memiliki pendidikan D3 - S2.

5. Berjenis kelamin Perempuan dan Lakilaki.
HASIL DAN PEMBAHASAN

1. Pelatihan divisi Human Capital pada PT Sumber Alfaria Trijaya Tbk (Head Office) Alam Sutera Kota Tangerang

Dari pembahasan pertama mengenai pelatihan yang diberikan perusahaan selama ini apakah sudah cukup baik. penulis dapat menyimpulkan pelatihan yang ada di PT Sumber Alfaria Trijaya Tbk (Head Office) Alam Sutera Tangerang belum optimal karena masih terdapat kekurangan dari segi materi dan metodenya seharusnya bisa lebih variatif dari periode sebelumnya agar tidak membuat kesan monoton dan membosankan bagi para peserta. Disisi lain dari itu, pelatihan yang diberikan perusahaan cukup menyesuaikan dengan kebutuhan karyawan.

Sebanding dengan teori Randall (2015) pelatihan yang baik merupakan pemberian pelatihan dengan metode yang tepat dan memiliki.

Dari pembahasan-pembahasan tersebut dapat disimpulkan betapa pentingnya karyawan baru maupun karyawan lama menghadiri undangan pelatihan secara tepat waktu, agar memiliki pengetahuan dan kemampuan dan keterampilan sesuai dengan tuntutan pekerjaan yang menjadi tanggung jawab. Melalui pelatihan karyawan juga akan lebih mengenal apa yang diperlukan oleh perusahaan, bagaimana strategi perusahaan dan apa yang menjadi sasaran perusahaan serta apa yang menjadi tujuan perusahaan. Dari situlah dapat dikatakan pelatihan berguna untuk wawasan / inovasi / skilll / motivasi bagi karyawan baru maupun karyawan lama. Yang paling pentingnya adalah kemampuan manajemen dalam perbaikan bidang Instruktur pelatihan agar dapat menumbuhkan motivasi karyawan dalam bekerja dan meningkatkan produktivitas kerja karyawan. Mengingat pentingnya manajemen, dalam hal ini manajemen yang baik sangat diperlukan. 
Pemberi materi Pelatihan yang belum optimal yang terkesan membosankan untuk para karyawan yang diberikan pelatihan seperti kutipan dari salah satu narasumber yang menyatakan "instruktur pelatihan mungkin kedepannya bisa menggunakan cara lain yang lebih baru agar cara menyampaikan materi tidak hanya itu itu saja" pemilihan instruktur yang tepat akan mempengaruhi lancar

2. Produktivitas kerja divisi Human Capital pada PT Sumber Alfaria Trijaya Tbk (Head Office) Alam Sutera Kota Tangerang

Membicarakan soal produktivitas kerja, perusahaan sangat mengapresiasi produktivitas kerja karyawan dimulai dari hal sederhana yaitu memberikan gift, reward, hingga yang sangat istimewa yaitu promosi jabatan, naik gaji, dll yang tentunya disesuaikan dengan prosedur dan penilaian KPI.

Penilaian produktivitas kerja penting dalam rangka pengembangan karyawan yang memiliki produktivitas tinggi maupun rendah. Menurut Sinungan dalam Fitriyanto (2015:19) manfaat dari penilaian produktivitas kerja adalah sebagai umpan balik pelaksanaan kerja untuk memperbaiki produktivitas kerja karyawan.

3. Analisis Pelatihan untuk

Meningkatkan Produktivitas Kerja Karyawan Divisi Human Capital pada PT Sumber Alfaria Trijaya Tbk (Head Office) Alam Sutera Kota Tangerang.

Efektivitas pelatihan karyawan merupakan hal yang sangat penting terutama untuk mengembangkan sumber daya manusia. Widodo, (2015:84) mengemukakan bahwa “Tujuan pelatihan yang dilakukan oleh perusahaan adalah untuk meningkatkan produktivitas, meningkatkan kualitas, mendukung perencanaan SDM, meningkatkan moral anggota, memberikan kompensasi yang tidak langsung, meningkatkan kesehatan dan keselamatan kerja, mencegah kedaluarsa kemampuan dan tidaknya dalam menyampaikan materi kepada karyawan yang diberikan pelatihan, ditinjau dari peserta masih terdapatnya peserta yang tidak serius dalam mengikuti pelatihan dan mengakibatkan ketidakhadiran dari karyawan tersebut. Dalam pelatihan ini sudah adanya evaluasi tetapi belum adanya evaluasi secara mendalam kepada masing-masing peserta.

pengetahuan personel, meningkatkan perkembangan kemampuan dan keahlian personel". mengenai hasil wawancara dengan Informan utama IVI dan Triangulasi I, Triangulasi II diketahui belum optimal, belum sesuai dengan yang diharapkan perusahaan. Diukur dari hasil star tercapai hanya tiga star. Sesuai dengan data penilaian produktivitas kerja perusahaan, menunjukan bahwa produktivitas kerja belum mencapai harapan dari perusahaan yaitu dengan target yang diharapkan mencapai lima star, tapi sejauh ini dalam kurun waktu tiga tahun terakhir hanya tiga star yang dicapai. Seperti hasil observasi dan wawancara yang penulis temukan, kurangnya loyalitas karyawan memprioritaskan yang menjadi aspek penilaian produktivitas kerja dari PT Sumber Alfaria Trijaya Tbk (Head Office) Alam Sutera Kota Tangerang.

\section{PENUTUP}

\section{Kesimpulan}

1. Pelatihan Orientasi Karyawan Baru (OKB) yang justru dianggap sebagai point penting sebagai bekal awal bergabung di sebuah perusahaan, tidak diikuti secara menyeluruh oleh peserta sesuai undangan yang diterbitkan perusahaan.

Sesuai data pelatihan, 3 periode / tahun belakangan pelatihan OKB masih terdapat peserta yang tidak hadir tepat waktunya. Meskipun tidak sampai 50\% peserta yang tidak hadir, namun penulis menyimpulkan bahwa hal tersebut membuat kegiatan pelatihan menjadi 
tidak maksimal, tidak efektif atau tidak efisien. Dari hasil wawancara ditemukan beberapa alasan atau penyebab pelatihan tidak diikuti secara menyeluruh oleh peserta undangan. Diantaranya adalah penjadwalan pelatihan yang belum terstuktur dengan baik, kemudian peserta tidak mendapat izin dari atasan mengikuti pelatihan karena bentrok dengan pekerjaan yang dianggap tidak bisa ditinggalkan pada saat itu, dan dikarenakan perusahaan kurang memastikan kepada paraatasan calon peserta undangan bahwa pelatihan harus (wajib) diikuti sesuai dengan jadwal yang sudah ditentukan PT Sumber Alfaria Trijaya Tbk (Head Office) Alam Sutera Kota Tangerang.

2. Tercatat pada tabel penilaian produktivitas kerja bahwa 3 tahun belakangan tidak ada peningkatan yang pencapaiannya maksimal sesuai target. Dari kegiatan observasi dan wawancara dengan para informan, penulis menemukan beberapa penyebab atau alasan dari kurang maksimalnya produktivitas kerja yang ada dari target perusahaan. Diantaranya kurangnya loyalitas karyawan memprioritaskan yang menjadi aspek penilaian produktivitas kerja, juga ditemukan bahwa masih terdapat beberapa karyawan yang tidak disiplin waktu (terlambat absensi),

3. Pelatihan penting bagi karyawan baru, karena karyawan yang memulai dengan langkah benar dan tepat cenderung lebih bahagia, produktif dan lebih lama menetap di perusahaan. Selain itu pelatihan juga dapat mengasah kemampuan serta meningkatkan produktivitas kerja karyawan. Dengan adanya pelatihan dan pengembangan, diharapkan produktivitas kerja pada perusahaan lebih efektif dan produktif karena telah memeroleh pengetahuan dan keterampilan sesuai yang dibutuhkan. Ini juga memungkinkan karyawan baru merasa cepat terhubung dengan perusahaan, budaya dan rekan kerja.

\section{DAFTAR PUSTAKA}

Affandi, A., et al. (2020). Optimization of MSMEs Empowerment in Facing Competition in the Global Market during the COVID-19 Pandemic Time. Systematic Reviews in Pharmacy, 11(11), 1506-1515.

Andhini, N. F. (2017). Manajemen Sumber Daya Manusia. Journal of Chemical Information and Modeling, 53(9), 1689-1699.

Bachri, B. S. (2010). Meyakinkan Validitas Data Melalui Triangulasi Pada Penelitian Kualitatif. Teknologi Pendidikan, 10, 46-62.

Badriyah, M. (2017) Manajemen Sumber Daya Manusia. Bandung: Pustaka Setia.

Bruno, L. (2019). Observasi. Journal of Chemical Information and Modeling, 53(9), 1689-1699. TeknikPengumpulan-Data Kualitatif.

Citra, K. P. N. (2013). Manajemen Sumber Daya Manusia. In Analisis pendapatan dan tingkat kesejahteraan rumah tangga petani (Vol. 53, Issue 9).

Fitriyanto. (2005). Pengaruh Motivasi Kerja dan Pengalaman Kerja terhadap Produktivitas Kerja. Pengaruh Motivasi Kerja Dan Pengalaman Kerja Terhadap Produktivitas Kerja, 11-56.

Gunawan, I. (2016). KUALITATIF Imam Gunawan. Pendidikan, 27. MetpenKualitatif.

Handoko, T. H. (2012). Manajemen Personalia dan Sumber Daya Manusia. Yogyakarta: BPFE

Hasibuan, M. S. P (2019). Manajemen Sumber Daya Manusia. Jakarta: Bumi Aksara.

Khurotin, N., \& Afrianty, T. W. (2018). Analisis pelatihan dan Pengembangan Sumber Daya Manusia di PT Beon Intermedia Cabang Malang. Jurnal Administrasi Bisnis, 64(1), 195-203.

Mangkunegara, A. P. (2015). Manajemen Sumber Daya Manusia Perusahaan. Jakarta: Remaja Rosdakarya. 
Margahana, H., \& Sari, S. S. (2019). Analisis Promosi Jabatan Terhadap Produktivitas Kerja Karyawan Pada PT. Fif Belitang Oku Timur. Jurnal AKTUAL, 16(1), 1.

Moleong, L. J, (2015). Metodologi Penelitian Kualitatif. Bandung: PT Remaja Rosdakarya

Rangkuti, F. (2013). Analisis SWOT Teknik Membedah Kasus Bisnis. Jakarta: Gramedia Pustaka Utama

Siagian, S. P (2014). Manajemen Strategic. Jakarta: Bumi Aksara.

Simamora, H. (2015). Manajemen Sumber Daya Manusia. Yogyakarta: STIEY
Sudiarto, S. (2018). Membangun Motivasi Kerja Guru Dalam Menyiapkan Sumber Daya Manusia Indonesia Yang Berkualitas (Analisis Teori Motivasi Abraham Maslow Di SMK Negeri 57 Jakarta). JENIUS (Jurnal Ilmiah Manajemen Sumber Daya Manusia), 1(3).

Suhartono, I., \& Sina, I. (2020). Smart People In Smart City Analisis Sumber Daya Manusia Dalam Rangka Mewujudkan Kota Tangerang Selatan Yang Cerdas. JENIUS (Jurnal Ilmiah Manajemen Sumber Daya Manusia), $3(2), 228-235$. 